\title{
Can Immigrant Employment Alleviate the Demographic Burden? The Role of Union Centralization
}

\author{
Alexander Kemnitz* \\ University of Mannheim \\ Department of Economics \\ D-68131 Mannheim
}

July 2005

\begin{abstract}
This paper investigates the effect of labor immigration on public pensions when wage setting by a centralized trade union leads to unemployment. It is shown that immigration improves the financial soundness of pay-as-you-go pensions if and only if it diminishes total employment. This occurs if the absolute value of the elasticity of labor demand exceeds the unemployment rate.
\end{abstract}

JEL classifications: F22, H55, J51

Keywords: Immigration, Public Pensions, Trade Union

*Tel: +49-621-1811798. Fax: +49-621-1811794. e-mail: kemnitz@econ.uni-mannheim.de. Thanks to Eckhard Janeba and Jovan Zamac for helpful comments. The usual disclaimer applies. 


\section{Introduction}

Opening up the borders for international migration is one heavily disputed response to the old-age security crisis faced by most industrialized countries. Proponents of such measures often point to the beneficial impact on the old-age dependency ratio arising from age differentials between average migrants and natives. ${ }^{1}$ Formalized by Razin and Sadka $(1999,2000)$ in the context of a full employment economy, this argument is a driving force behind the net positive fiscal effect of immigration identified by quantitative studies (Storesletten, 2000; Sinn, 2001).

Obviously, the strength of this reasoning is intimately linked to the aggregate employment effects of immigration. However, these effects are ambiguous, once the unrealistic assumption of full employment is abandoned (Schmidt et al., 1994; Razin and Sadka, 1995; Fuest and Thum, 2000). In the binding minimum wage economy of Razin and Sadka (1995), for example, immigration has no consequences for total employment, which renders a positive effect on pensions impossible.

The literature on immigration to economies with labor market distortions typically does not consider pay-as-you-go pensions. Nevertheless, it suggests that the stabilizing role of immigration for public pensions emerges in those settings where wages are flexible enough to absorb some of the increased labor supply. This presumption is corroborated by the findings in Kemnitz (2003), the only study known to the author, which explicitly links immigration and public pensions in the presence of unemployment.

Explaining unemployment as the result of trade union power, Kemnitz (2003) adheres to the standard model where unions are organized at the firm level. However, as emphasized by a number studies originating with Calmfors and Driffill (1988), there is significant international variation in the degree of union centralization. Therefore, firm level bargaining may be a poor description of the wage setting process in many countries, with unexplored implications for the labor market effects of immigration.

This paper scrutinizes the existence of beneficial effects of immigration on public pensions in an economy where the labor market is dominated by a large trade union pursuing the interest of workers. It shows that the consideration of union centralization reverts the above argument in favor of immigrant workers. In any unemployment

1 However, this argumentation neglects the fact that these immigrants become entitled for later pension benefits. Therefore, the continuity of the improvement depends on the pension contributions by the immigrant offspring. See Razin and Sadka (1999), Casarico and Devillanova (2003) and Krieger (2004) for a discussion. 
equilibrium, immigration is found to harm public pensions whenever it increases the total number of jobs. An alleviation of the demographic burden of social security occurs only if total employment declines. Whether this is the case depends on the existing level of unemployment in the host economy.

The economic intuition behind this result rests on the fact that the trade union chooses a wage in the inelastic part of labor demand. If it did not, the union could increase the expected utility of its members by a wage cut: with elastic labor demand, a wage reduction would not only mitigate income uncertainty by lowering the unemployment rate, but also increase the wage bill, the total amount of resources available to the workforce. But given the inelasticity of labor demand, any job creation due to immigration necessarily erodes the wage bill, the base of public pension financing.

The paper is organized as follows. The next section introduces the model and derives the labor market equilibrium. Section 3 deals with the effects of immigration. Some concluding remarks are offered in Section 4.

\section{The Model}

Consider an an economy of two overlapping generations where people work in the first period of life, supplying inelastically one unit of labor, and retire in the second. The size of each native generation is normalized to unity: $N_{t}=1$. However, the workforce increases unexpectedly in period $t$ due to the immigration of $M_{t}$ workers from other countries.

In every period, atomistic firms produces the single output good by a standard neoclassical production function combining physical capital $K$ and labor $L$ :

$$
Y_{t}=F\left(K_{t}, L_{t}\right)=L_{t} f\left(k_{t}\right)
$$

where $k_{t}=K_{t} / L_{t}$ is the capital intensity. Profit maximization leads to the usual marginal productivity conditions:

$$
\begin{aligned}
r_{t} & =f^{\prime}\left(k_{t}\right), \\
w_{t} & =f\left(k_{t}\right)-k_{t} f^{\prime}\left(k_{t}\right) .
\end{aligned}
$$

The capital market is competitive and the interest rate $r_{t}$ adjusts such that the existing capital stock is fully utilized. However, aggregate employment is endogenous, as firms 
hire labor only up to the point where its marginal productivity equals the wage rate $w_{t}$ set by the trade union. The determinants of union behavior will be discussed below. From (2) and (1), a wage increase reduces employment and the interest rate:

$$
\begin{aligned}
\frac{\partial L_{t}}{\partial w_{t}} & =\frac{L_{t}}{f^{\prime \prime}\left(k_{t}\right) k_{t}^{2}}<0, \\
\frac{\partial r_{t}}{\partial w_{t}} & =-\frac{1}{k_{t}}<0
\end{aligned}
$$

For further reference, we define the elasticity of labor demand as: $\varepsilon_{t}=\frac{f\left(k_{t}\right)-k_{t} f^{\prime}\left(k_{t}\right)}{f^{\prime \prime}\left(k_{t}\right) k_{t}^{2}}<0$. Every individual born in period $t$ receives utility out of consumption in both periods of life according to the utility function:

$$
U_{t}=U\left(c_{t}^{i}, z_{t+1}^{i}\right)
$$

To simplify matters, (5) is the same for all individuals and obeys the usual concavity and Inada properties.

Let the employment status of a young household be denoted by $i \in\{E, U\}$. Employed individuals earn a net wage $\left(1-\tau_{U}-\tau_{P}\right) w_{t}$, where $\tau_{U}$ and $\tau_{P}$ are the contribution rates to unemployment insurance and public pensions. Unemployed individuals receive the unemployment benefit $b_{t}$, whereas the current old are paid the pension $p_{t}^{i}$. Hence, the consumption constraints are:

$$
\begin{aligned}
c_{t}^{i} & =d\left(1-\tau_{U}-c\right) w_{t}+(1-d) b_{t}-s_{t}^{i}, \\
z_{t+1}^{i} & =p_{t+1}^{i}+\left(1+r_{t+1}\right) s_{t}^{i}
\end{aligned}
$$

where $s_{t}^{i}$ are private savings and $d=1 \Longleftrightarrow i=E$ and $d=0 \Longleftrightarrow i=U$. Following Cassamatta et al. (2000), the public pension consists of a demogrant benefit $\bar{p}_{t}$ and an earnings related component where $\Omega_{t}$ denotes the equivalence factor:

$$
p_{t+1}^{i}=\bar{p}_{t+1}+\Omega_{t+1}\left(d w_{t}+(1-d) b_{t}\right)
$$

After the employment status is known, individuals decide on the amount of individual old-age savings, characterized by the first-order condition:

$$
u_{1}^{i}+R u_{2}^{i}=0
$$


where we abbreviate notation according to: $u_{1}^{i}=u_{1}\left(c_{t}^{i}, z_{t+1}^{i}\right)$. Individual indirect utility in state $i$ can be written as $v\left(I_{t}^{i}, r_{t+1}\right), I_{t}^{i}=c_{t}^{i}+z_{t+1} /\left(1+r_{t+1}\right)$ denoting discounted lifetime income. This leads to the expected indirect utility of a generation $t$ individual:

$$
V_{t}=\left(1-\eta_{t}\right) v\left(I_{t}^{E}, r_{t+1}\right)+\eta_{t} v\left(I_{t}^{U}, r_{t+1}\right)
$$

where $\eta_{t}$ is the unemployment probability of a member of generation $t$ to be unemployed during youth. By the law of large numbers, $\eta_{t}$ is also equal to the unemployment rate. We posit that employment chances are distributed equally across all households, including immigrants: $\eta_{t}=\frac{N_{t}+M_{t}-L_{t}}{N_{t}+M_{t}}$. Moreover, we assume that individuals are risk averse, that is indirect utility is concave in income: ${ }^{2}$

$$
\frac{\partial v}{\partial I_{t}^{i}}>0, \frac{\partial^{2} v}{\partial I_{t}^{i^{2}}}<0 .
$$

For simplicity, physical capital depreciates after one period. As a consequence, the capital stock in every period is determined by the savings of the last period:

$$
K_{t+1}=\eta_{t}\left(N_{t}+M_{t}\right) s_{t}^{U}+\left(1-\eta_{t}\right)\left(N_{t}+M_{t}\right) s_{t}^{E}
$$

The welfare state of the economy cares for both the unemployed and the elderly. Taking both contribution rates as constant over time, budget balance requires:

$$
\begin{aligned}
& \tau_{U} w_{t} L_{t}=b_{t}\left(N_{t}+M_{t}-L_{t}\right), \\
& \tau_{P} w_{t} L_{t}=\left(N_{t-1}+M_{t-1}\right) \bar{p}_{t}+\Omega_{t}\left(w_{t-1} L_{t-1}+b_{t}\left(N_{t-1}+M_{t-1}-L_{t-1}\right)\right) .
\end{aligned}
$$

The assumption of a constant $\tau_{U}$ is usual in the literature, see Razin and Sadka (1999) and Casarico and Devillanova (2003). In the context of small unions, Kemnitz (2004) has shown that a constant contribution rate to unemployment insurance is more conducive to wage flexibility and hence immigrant employment creation than other social policies.

All workers of a generation are organized in a trade union, acting in the current interest of workers. In contrast to the existing literature (Corneo and Marquardt, 2000; Irmen and Wigger, 2002), this union is large in the sense that it controls the economy-wide wage.

2 This property results from various assumptions on direct utility (5), the most obvious one being additive separability: $U_{12}=0$. 
In any standard overlapping-generation framework like the present one, the conflict between labor and capital is necessarily also a conflict between the young and the old, since present union members become capitalists later in life. Therefore, maximizing the current utility of workers has to be distinguished from maximizing expected lifetime utility. In the latter case, the union would have to take the consequences of current wage setting on future interest rates and wages via aggregate savings into account. But as a higher return on capital impinges on the wage, such a union would actively pursue the interest of future capitalists at the expense of future workers. ${ }^{3}$ This would seriously blur the general identification of a trade union as the agent representing labor. Hence, we restrict the concern of the union to the current utility of workers, internalizing the effect of its decisions on the unemployment rate and welfare state budgets, but paying no attention to dynamic repercussions on factor prices.

As a consequence, the problem of the trade union in period $t$ is to maximize (9) with respect to $w_{t}$ for a given capital stock $K_{t}$ and future interest rate $r_{t+1}$, taking the marginal productivity conditions (1) and (2), individual utility maximization (8) and the welfare state budgets (11) and (12) into account. Using $v_{t}^{i}=v_{t}^{i}\left(I_{t}^{i}, r_{t+1}\right)$ as a shortcut, we have the first order condition:

$$
\frac{\partial L_{t}}{\partial w_{t}} v_{t}^{E}+L_{t} \frac{\partial v_{t}^{E}}{\partial I_{t}^{E}} \frac{\partial I_{t}^{E}}{\partial w_{t}}-\frac{\partial L_{t}}{\partial w_{t}} v_{t}^{U}+\left(N_{t}+M_{t}-L_{t}\right) \frac{\partial v_{t}^{U}}{\partial I_{t}^{u}} \frac{\partial I_{t}^{U}}{\partial w_{t}} \leq 0
$$

with strict equality if $L_{t}<N_{t}+M_{t}$.

Proposition 1. In any labor market equilibrium with unemployment, the union sets a wage in the inelastic region of labor demand.

Proof. Unemployment results if the second-order condition $\frac{\partial^{2} V_{t}}{\partial w^{2}}<0$ is fulfilled and (13) holds with equality. Multiplying that expression by $w / L$ and inserting:

$$
\begin{aligned}
\frac{\partial I_{t}^{E}}{\partial w_{t}} & =\left(1-\tau_{U}-\tau_{P}\right)+\left(\frac{\Omega_{t+1}}{1+r_{t+1}}\right)=\frac{I_{t}^{E}-\frac{\bar{p}_{t+1}}{1+r_{t+1}}}{w_{t}}, \\
\frac{\partial I_{t}^{U}}{\partial w_{t}} & =\left(1+\frac{\Omega_{t+1}}{1+r_{t+1}}\right) \frac{\tau_{U} L_{t}\left[\left(N_{t}+M_{t}-L_{t}\right)\left(1+\varepsilon_{t}\right)+\varepsilon_{t} L_{t}\right]}{\left(N_{t}+M_{t}-L_{t}\right)^{2}} \\
& =\left(1+\varepsilon_{t}\right) \frac{I_{t}^{E}-\frac{\bar{p}_{t+1}}{1+r_{t+1}}}{w_{t}}+\frac{\left(1+\frac{\Omega_{t+1}}{1+r_{t+1}}\right) \tau_{U} \varepsilon_{t} L_{t}^{2}}{\left(N_{t}+M_{t}-L_{t}\right)^{2}}
\end{aligned}
$$

3 This complication is original to the assumption of a large union. As emphasized by Devereux and Lockwood (1991), the wage policy of a small union has a negligible impact on aggregate savings and hence the interest rate. 
leads to:

$$
\begin{aligned}
\varepsilon_{t}\left[v\left(I_{t}^{E}\right)-v\left(I_{t}^{U}\right)\right] & +\frac{\partial v_{t}^{E}}{\partial I_{t}^{E}}\left(I_{t}^{E}-\frac{\bar{p}_{t+1}}{1+r_{t+1}}\right)+\varepsilon_{t} \frac{\partial v_{t}^{U}}{\partial I_{t}^{U}}\left(I_{t}^{U}-\frac{\bar{p}_{t+1}}{1+r_{t+1}}\right) \\
& +\left(1+\varepsilon_{t}\right) \tau_{U} w_{t} \frac{\partial v_{t}^{U}}{\partial I_{t}^{U}}\left(1+\frac{\Omega_{t+1}}{1+r_{t+1}}\right)=0
\end{aligned}
$$

Expansion by $\varepsilon_{t} \frac{\partial v_{t}^{E}}{\partial I_{t}^{E}}\left(I_{t}^{E}-\frac{\bar{p}_{t+1}}{1+r_{t+1}}\right)$ gives:

$$
\begin{aligned}
& \varepsilon_{t}\left[v\left(I_{t}^{E}\right)-\frac{\partial v_{t}^{E}}{\partial I_{t}^{E}}\left(I_{t}^{E}-\bar{p}_{t+1}\right)-v_{t}^{U}+\frac{\partial v_{t}^{U}}{\partial I_{t}^{U}}\left(I_{t}^{U}-\frac{\bar{p}_{t+1}}{1+r_{t+1}}\right)\right] \\
& \quad+\left(1+\varepsilon_{t}\right)\left[\frac{\partial v_{t}^{U}}{\partial I_{t}^{U}} \tau_{U} w_{t}\left(1+\frac{\Omega_{t+1}}{\left(1+r_{t+1}\right)}\right)+\frac{\partial v_{t}^{E}}{\partial I_{t}^{E}}\left(I_{t}^{E}-\frac{\bar{p}_{t+1}}{1+r_{t+1}}\right)\right]=0 .
\end{aligned}
$$

Because $V(I)-\frac{\partial V}{\partial I}(I-x)$ increases in $I$ :

$$
\frac{\partial\left[V(I)-\frac{\partial V}{\partial I}(I-x)\right]}{\partial I}=-\frac{\partial^{2} V}{\partial I^{2}}(I-x)>0,
$$

the first row in (14) has a negative sign. The term in square brackets in the second row being unambiguously positive, (14) can hold only if $\varepsilon>-1$, rendering the second row positive.

Increasing the wage has two effects. On the one hand, the reduction in employment diminishes the expected utility of risk averse workers. On the other hand, it affects the wage bill, the total income available to the workforce. In any part of the labor demand curve which is not inelastic, a wage reduction improves equality without sacrificing total income, and therefore increases the expected utility of workers. Hence, any equilibrium wage leading to unemployment must trade off the higher income risk with the higher total income due to a wage increase, which requires labor demand to be inelastic in equilibrium.

From a modelling perspective, the existence of an unemployment equilibrium in the presence of union centralization is a delicate issue. Layard et al. (1991) set forth a number of arguments why union centralization is likely to lead to full employment, including the fact that unemployment can never result when the technology implies a generally elastic labor demand. However, empirical evidence supports neither such a technology nor an absence of unemployment in economies with centralized wage setting. ${ }^{4}$ This makes an analysis of the unemployment equilibrium worthwhile.

4 According to Hamermesh (1993), Table 3.2, estimates of the wage elasticity of unconditional factor demand, which is the relevant variable here, average around unity. Cahuc and Zylberberg (2004), Table 12.13 report an average unemployment rate in centralized economies of $9 \%$ in 1993 . 


\section{The Effects of Immigration}

We now consider the impact of immigration on employment and the welfare state. To simplify the exposition, we assume that unemployment exists before and after immigration. This will be discussed at the end of this section.

Proposition 2. Immigration leads to a rise of the unemployment benefit and has an ambiguous impact on total employment. Employment rises (falls) if the unemployment rate is lower (higher) than the absolute value of the elasticity of labor demand.

Proof. From (14):

$$
\frac{d L_{t}}{d M_{t}}=-\frac{\frac{\partial^{2} V_{t}}{\partial w_{t} \partial M_{t}}}{\frac{\partial^{2} V_{t}}{\partial w_{t} \partial L_{t}}}
$$

where the denominator is positive due to the second order condition of the union's maximization problem $\left(\frac{\partial^{2} V_{t}}{\partial w_{t}^{2}}<0\right)$. The sign of the numerator:

$$
\frac{\partial^{2} V_{t}}{\partial w \partial M}=-\frac{\partial^{2} v_{t}^{U}}{\partial I_{t}^{U^{2}}}\left(1+\frac{\Omega_{t+1}}{1+r_{t+1}}\right)^{2} \frac{\tau_{U} w_{t} L_{t}}{\left.N_{t}+M_{t}-L_{t}\right)^{2}}\left[\tau_{U}(1+\varepsilon) w_{t}+\varepsilon b_{t}\right]
$$

equals the sign of the last term in square brackets. Employing (11) yields:

$$
\frac{\partial^{2} V_{t}}{\partial w \partial M} \gtreqless 0 \Longleftrightarrow L_{t} \gtreqless(1+\varepsilon)\left(N_{t}+M_{t}\right)
$$

and hence $\frac{d L_{t}}{d M_{t}} \gtreqless 0 \Longleftrightarrow L_{t} \lesseqgtr(1+\varepsilon)\left(N_{t}+M_{t}\right)$. Due to $\varepsilon<-1$, the direction of the employment effect is ambiguous. Because of $L_{t}=\left(1-\eta_{t}\right)\left(N_{t}+M_{t}\right)$ :

$$
\frac{d L_{t}}{d M_{t}} \gtreqless 0 \Longleftrightarrow \eta_{t} \gtreqless-\varepsilon_{t} .
$$

The unemployment benefit reacts according to:

$$
\frac{d b_{t}}{d M_{t}}=-\frac{w_{t}}{\varepsilon_{t}}\left[L_{t}-\left(1+\varepsilon_{t}\right)\left(N_{t}+M_{t}\right)\right] \frac{d L_{t}}{d M_{t}},
$$

which is positive because the term in square brackets has the same sign as $\frac{d L_{t}}{d M_{t}}$. $\square$ If the wage (and hence total employment) remained at the pre-migration level, immigration would decrease the unemployment benefit and make the state of unemployment more likely. Because members are risk averse, the union adjusts the wage to correct for this imbalance. However, the inelasticity of labor demand makes the direction of this adjustment ambiguous: cutting the wage brings more individuals into employment on 
the one hand, but diminishes total contributions on the other hand. If the unemployment rate is very high, the effect on the dependency ratio is stronger and the union mitigates the demanded wage. For low unemployment, the total contribution effect dominates and the wage rises.

While immigration increases social protection for the unemployed unambiguously, we now consider the effect on public pensions.

Proposition 3. Immigration alleviates the demographic burden only if it decreases total employment.

Proof. Let $P_{t}=\tau_{P} w_{t} L_{t}$ denote the total amount paid to the retirees in period $t$. Immigration affects these revenues according to:

$$
\frac{\partial P_{t}}{\partial M_{t}}=\frac{\tau_{P} w_{t}}{N_{t-1}+M_{t-1}}(\underbrace{1+\frac{1}{\varepsilon}}_{<0}) \frac{d L_{t}}{d M_{t}} . \square
$$

With the number of pensioners and the contribution rate being fixed, pension payments to the old are a given fraction of the total wage bill. This wage bill increases only when total employment decreases. This turns the usual argument that immigration helps the welfare state through higher employment upside down.

Combining Proposition 2 and 3, one can conclude that immigration helps the soundness of public pensions only if the unemployment rate exceeds the absolute value of the elasticity of labor demand. In the light of the empirical estimates on $\varepsilon_{t}$ lying around unity, this is unlikely to be the case. Rather, our results predict immigration to increase aggregate employment and to harm public old-age security.

Up to here, we have presumed that the economy remains in an unemployment equilibrium. However, one can not rule out that the union sets the full employment wage after immigration. However, this would mean that immigration is a perfect cure to the whole problem of unemployment. But even if that happened, the total wage bill need not increase. Consider for example a CES production function with an elasticity of substitution below unity, where labor demand is inelastic for all employment levels above a certain threshold value. ${ }^{5}$ As the shift to the corner solution implies a rise in employment, the new equilibrium must feature inelastic labor demand whenever unemployment prevailed before immigration.

5 For elasticities of substitution of unity and above, labor demand is unambiguously elastic everywhere. 


\section{Conclusion}

This paper puts some caution on the conventional wisdom that immigrant labor improves the financial sustainability of pay-as-you-go financed pensions. In a model with centralized wage setting, it was shown that immigration benefits the retirees only if total employment declines. The creation of additional jobs, in contrast, harms old-age security. This finding originates in the fact that labor demand is inelastic in equilibrium. Consequently, any employment increase reduces the wage bill, the source of public pension financing.

It should be stressed that inelasticity of labor demand can also hold in other labor market settings, including full employment. However, the existing literature on the effect of immigration and public pensions (Razin and Sadka, 2000; Casarico and Devillanova, 2003; Kemnitz, 2003) has masked this possibility by relying on technologies with generally elastic labor demands. This paper, in contrast, highlights the structural interrelation between inelasticity and centralized union wage setting.

In line with the public debate, the analysis has focussed on the short-run impact of immigration on public pensions, which should clearly be disentangled from utility effects. Consider a current retiree, the income of whom consists of both pension payments and capital returns. Immigration exerts countervailing effects on both sources: when employment increases, total pension contributions decrease but the interest rate rises, whereas the opposite is true for an employment decline. Therefore, the attitude of the retirees towards immigration is ambiguous. Also, the impact on the income of the current young is unclear. Immigration increases the unemployment benefit, but increases or decreases net earnings of the employed, depending on the direction of the wage adjustment. Accordingly, the probability to enter the state of employment changes.

For the overall utility of the young, the interest rate prevailing in the next period plays a crucial role. Among others, the return to capital in a period depends on current wage setting and on the level of the capital stock, which is affected by former wage setting via savings decisions. Therefore, any conclusions are highly sensitive to assumptions on the income dependency of the savings ratio, the relation between the capital stock and the elasticity of labor demand and the pension contribution rate, determining the mix between private and public funding of old-age consumption. These aspects, not lying at the heart of the public debate and distracting attention from the key mechanism behind our results, are left for future research. 


\section{References}

Cahuc, P. and A. Zylberberg (2004): Labor Economics, MIT Press.

Calmfors, L. and J. Driffill (1988): Bargaining Structure, Corporatism, and Macroeconomic Performance, Economic Policy 6, 16-61.

Casarico, A. and Devillanova, C. (2003): Social Security and Migration with Endogenous Skill Upgrading, Journal of Public Economics 87, 773-797.

Cassamatta, G., H. Cremer and P. Pestieau (2000): The Political Economy of Social Security, Scandinavian Journal of Economics 102, 503-522.

Corneo, G. and M. Marquardt (2000): Public Pensions, Unemployment Insurance, and Growth, Journal of Public Economics, 75, S.293-311.

Devereux, M.B. and B. Lockwood (1991): Trade Unions, Non-Binding Wage Agreements, and Capital Accumulation, European Economic Review 35, 1411-1426.

Fuest, C. and Thum, M. (2000): Welfare Effects of Immigration in a Dual Labor Market, Regional Science and Urban Economics 30, 551-563.

Hamermesh, D. (1993): Labor Demand, Princeton University Press.

Irmen, A. and B. U. Wigger (2002): Trade Union Objectives and Economic Growth, Finanzarchiv, 59, 49-67.

Kemnitz, A. (2003): Immigration, Unemployment and Pensions, Scandinavian Journal of Economics, 105, 31-47.

Kemnitz, A. (2004): Unemployment Insurance, Immigrants' Skills, and Native Earnings, Finanzarchiv, 60, 111-139.

Krieger, T. (2004): Fertility Rates and Skill Distribution in Razin and Sadka's MigrationPension Model: A Note, Journal of Population Economics 17, 177-182.

Layard, R., Nickell, S. and R. Jackman (1991): Unemployment. Macroeconomic Performance and the Labour Market, Oxford University Press.

Razin, A. and E. Sadka (1995): Resisting Migration: Wage Rigidity and Income Distribution, American Economic Review 85, 312-316.

Razin, A. and E. Sadka (1999): Migration and Pension with International Capital Mobility, Journal of Public Economics, 74, 141-150.

Razin, A. and E. Sadka (2000): Unskilled Migration: A Burden or a Boon for the Welfare State? Scandinavian Journal of Economics 102, 463-479. 
Schmidt, C. M., Stilz, A. and Zimmermann, K.F. (1994): Mass Migration, Unions, and Government Intervention, Journal of Public Economics 55, 185-201.

Sinn, H. W. (2001): The Value of Children and Immigrants in a Pay-As-You-Go Pension System : A Proposal for a Partial Transition to a Funded System, ifo-Studien 47, $77-94$.

Storesletten, K. (2000): Sustaining Fiscal Policy Through Immigration, Journal of Political Economy 108, 300-323. 